\title{
Glossopharyngeal neuralgia due to exposed glossopharyngeal nerve post tonsillectomy and transoral styloidectomy
}

\author{
Ajith Keragodi Mahalingappa, Richa Gupta*, Swathi Ramakrishnan
}

Department of Otorhinolaryngology, SSIMS and RC, Davangere, Karnataka, India

Received: 20 June 2020

Revised: 21 July 2020

Accepted: 29 July 2020

*Correspondence:
Dr. Richa Gupta,
E-mail: richagupta227mn@gmail.com

Copyright: () the author(s), publisher and licensee Medip Academy. This is an open-access article distributed under the terms of the Creative Commons Attribution Non-Commercial License, which permits unrestricted non-commercial use, distribution, and reproduction in any medium, provided the original work is properly cited.

\begin{abstract}
Glossopharyngeal neuralgia $(\mathrm{GN})$ is a rare facial pain syndrome, characterized by paroxysm of excruciating radiating pain in the sensory distribution of the auricular and pharyngeal branches of glossopharyngeal and vagus nerves. In relation to the tonsil, the glossopharyngeal nerve passes deep to the styloid process and related muscles attaching to styloid process. The lingual branch of the glossopharyngeal nerve provides sensation to the posterior tongue and enters the tongue base by traveling through the constrictor muscles in the area of the lingulotonsillar sulcus. Post tonsillectomy fossa with exposed nerve causing intractable pain is a rare entity. We report a case of 64 year male patient, post tonsillectomy and transoral styloidectomy, with complaint of severe throat pain on left side for 2 years, radiating upwards to the ipsilateral ear, face and eye. Glossopharyngeal nerve and its branches were found exposed in the posterior and inferior aspect of tonsillar bed. Surgical resection of exposed glossopharyngeal nerve and its branches was carried out in view of failure to respond to oral carbamazepine. Patient was symptom free during 10 months of follow up visit. GN is a rare condition following tonsillectomy and styloidectomy. Radical dissection of tonsillar bed during tonsillectomy and not suturing tonsillar bed properly after styloidectomy can lead to exposure of glossopharyngeal nerve and its branches, resulting in intractable GN.
\end{abstract}

Keywords: Exposed glossopharyngeal nerve, Glossopharyngeal neuralgia, Post tonsillectomy, Transoral styloidectomy

\section{INTRODUCTION}

Glossopharyngeal neuralgia $(\mathrm{GN})$ is a rare facial pain syndrome, characterized by paroxysm of excruciating radiating pain in the sensory distribution of the auricular and pharyngeal branches of glossopharyngeal and vagus nerves. ${ }^{1}$ The attack is triggered by chewing, yawning, swallowing excessive mouth movements. The incidence of GN is 0.8 per 100,000 person-years. ${ }^{2}$ Majority of cases of GN are idiopathic. In relation to the tonsil, the glossopharyngeal nerve passes deep to the styloid process and related muscles attaching to styloid process. These branches/fibres can get displaced superficially after tonsil bed dissection during styloid excision. The lingual branch of the glossopharyngeal nerve provides sensation to the posterior tongue and enters the tongue base by traveling through the constrictor muscles in the area of the lingulotonsillar sulcus. ${ }^{3}$

This case was reported in view of rarity of glossopharyngeal nerve exposure leading to GN, regeneration of nerve after excision of short segment of nerve.

\section{CASE REPORT}

We report a case of 64 year male patient, post tonsillectomy and transoral styloidectomy, with complaint of paroxysms of severe throat pain on left side for 2 years, radiating upwards to the ipsilateral left ear, face and eye, 
on swallowing. Patient underwent tonsillectomy and transoral styloidectomy elsewhere 2 years back for chronic tonsillitis with elongated styloid process. Oropharyngeal examination revealed post tonsillectomy status on the left side. GN and its branches were found exposed in the tonsillar bed (Figure 1). Uvula was absent. On touching the exposed nerve with a probe, patient experienced excruciating shooting pain radiating to ipsilateral ear, face and eye. Other ENT examination was found to be normal.

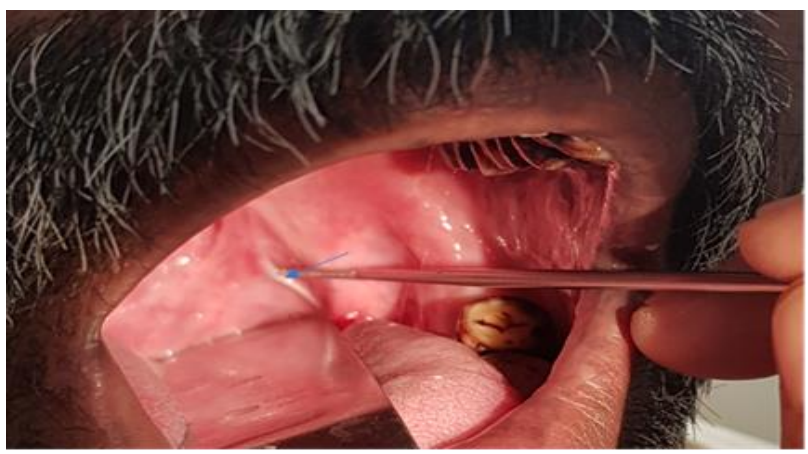

Figure 1: Arrow showing exposed nerve in tonsil.

Topical lignocaine $10 \%$ was sprayed over the exposed part of the nerve and lignocaine $2 \%$ local infiltration was given around the nerve which relieved the pain for few minutes and few hours respectively.

Patient was started on tab carbamazepine $100 \mathrm{mg}$ BD (twice a day) with starting dose and dose was escalated to maximum $800 \mathrm{mg} /$ day after normal complete blood count (CBC) report. Due to giddiness symptoms and GI intolerance patient discontinued the medication. Surgical resection of nerve was planned (Figure 2-4).

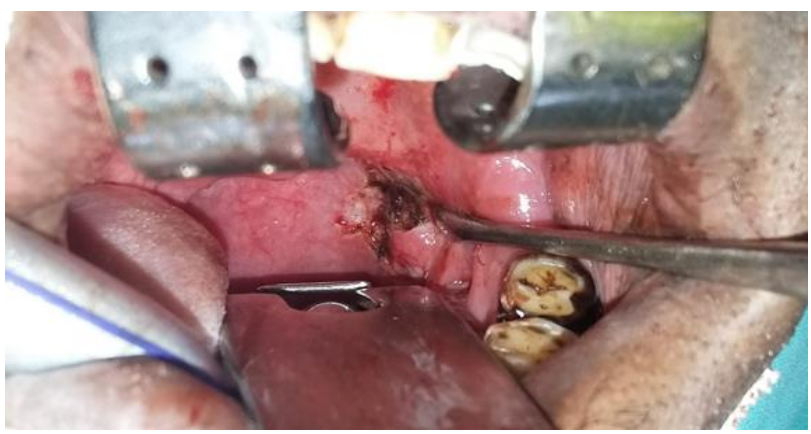

Figure 2: Intra-operative nerve resection.

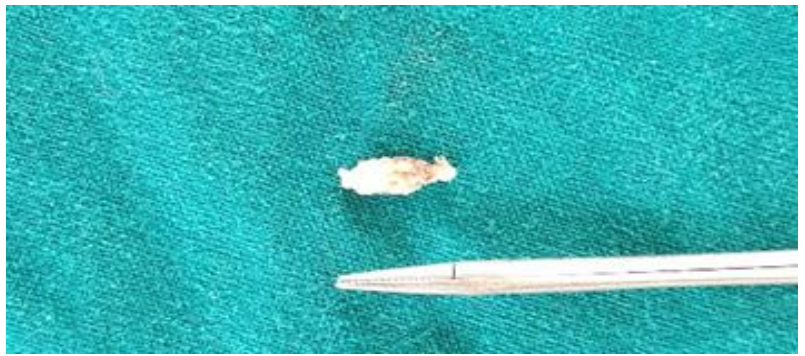

Figure 3: Resected nerve of about $1 \mathrm{~cm}$.

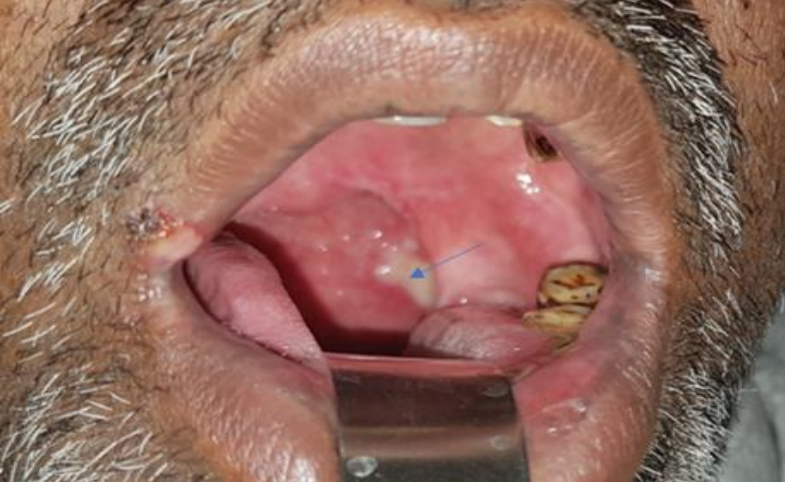

Figure 4: Post-operative day 20, slough noted in tonsillar bed.

Nerve section was sent for HPE. Histopathology report showed mild chronic inflammatory infiltrate with congested blood vessels along with nerve tissue. Follow up after 2 months showed completely healed tonsillar fossa (Figure 5).

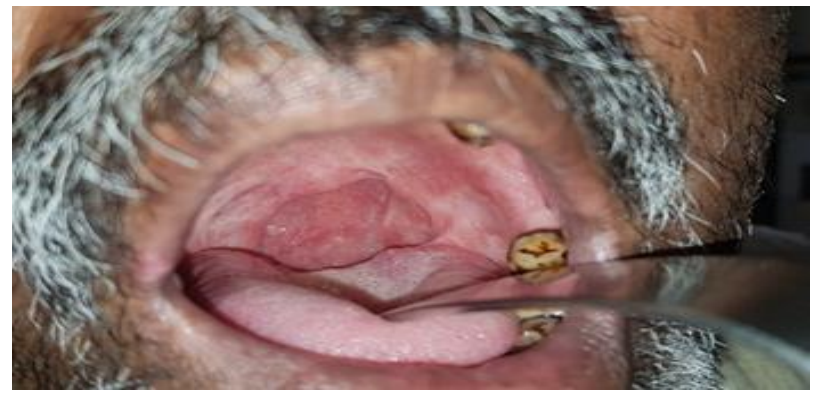

Figure 5: Follow up after 2 months showing completely healed tonsillar fossa.

Patient presented with similar complaints of intractable throat pain, referred pain to ear, face and eye, aggravated on swallowing following 2 months of symptom free interval. Patient was again restarted on oral carbamazepine $100 \mathrm{mg} \mathrm{BD}$ and patient discontinued the medication due to giddiness and drowsiness. Oropharyngeal examination revealed- the GN that had regenerated in the tonsillar bed (Figure 6).

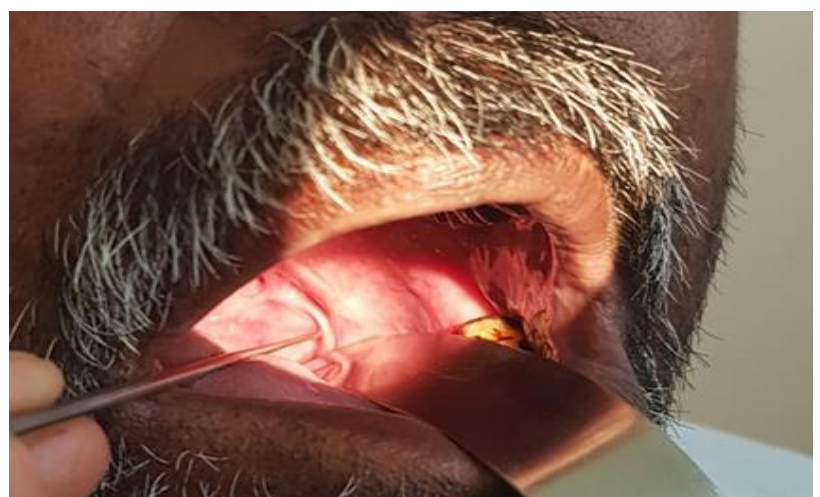

Figure 6: The glossopharyngeal nerve that had regenerated in the tonsillar bed. 
In consultation with neurologist this time re excision of nerve was planned. A long segment of glossopharyngeal nerve with its branches measuring about $3 \mathrm{~cm}$ was excised and sent for holoprosencephaly (HPE) (Figure 7 and 8).

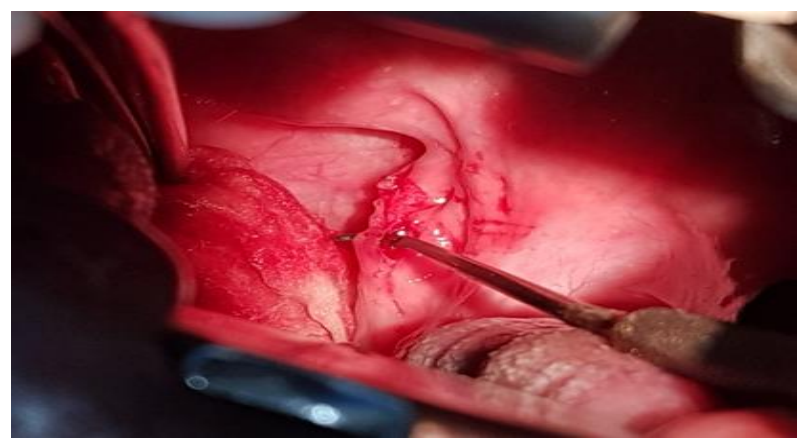

Figure 7: Arrow in the image showing nerve and its branches being traced intra-operatively.

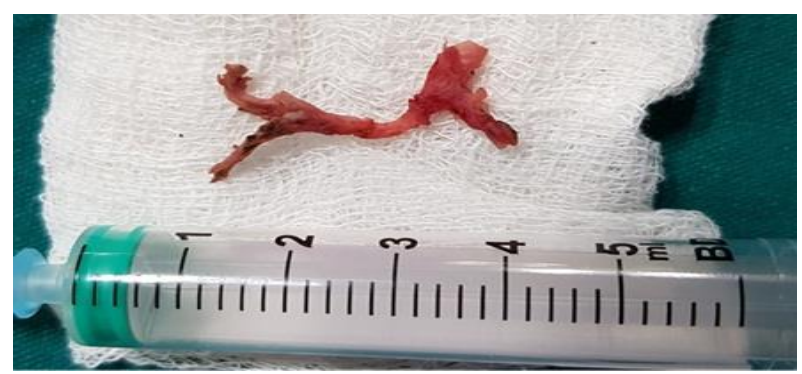

Figure 8: Pre-operative nasal endoscopy.

Histopathological report is shown in Figure 9. Patient was symptom free for 10 months of regular frequent follow up visit (Figure 10).

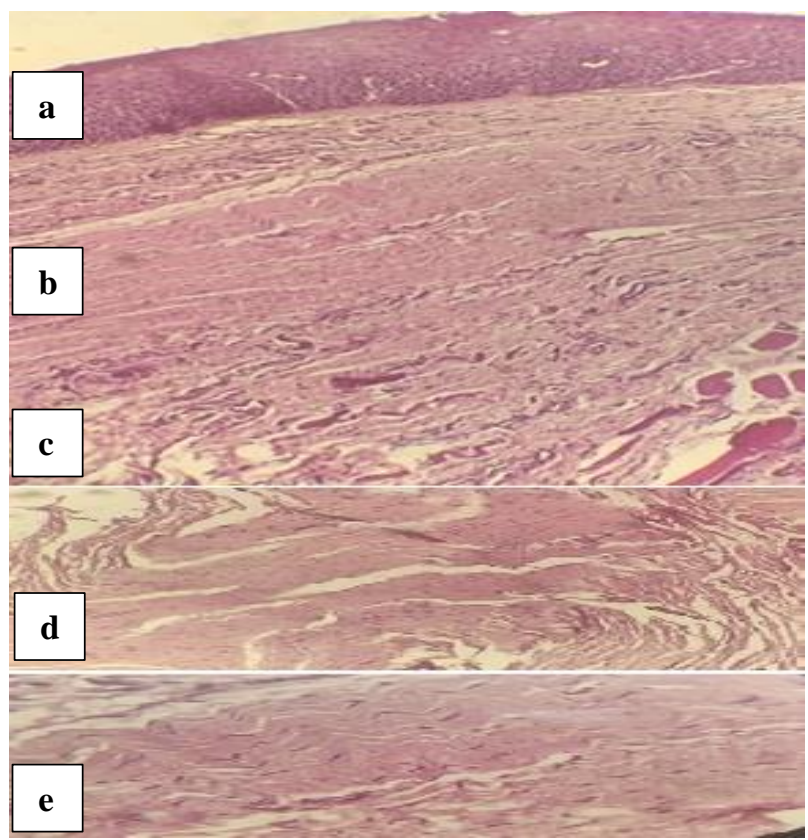

Figure 9: Low power magnification of nerve section (a) epithelium (b) nerve (c) skeletal muscle (d) and (e) high power view of nerve section.

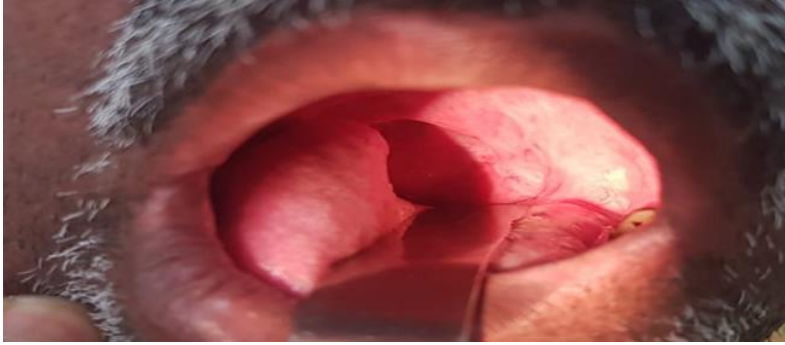

Figure 10: Follow up image of patient no regeneration is seen.

\section{DISCUSSION}

After exiting the jugular foreman, the glossopharyngeal nerve is located between the internal carotid artery and internal jugular vein, descending deep to the styloid process. $^{3}$

GN is divided into 3 segments based on its relationship with stylopharyngeus muscle, i.e. upper, middle and lower.

Upper segment starts from jugular foramen to intersection of glossopharyngeal nerve with superior border of stylopharyngeus muscle.

Middle segment starts from intersection of the GN with superior border of stylopharyngeus muscle to intersection of the glossopharyngeal nerve with the inferior border of the stylopharyngeus muscle.

Lower segment starts from to intersection of the GN with the inferior border of the stylopharyngeus muscle to its end at the tongue base. ${ }^{3}$

The middle segment of the GN is covered by the stylopharyngeus muscle anteriorly. In this segment, it gives off branches innervating the stylopharyngeus muscle and branches to pharyngeal wall. ${ }^{3}$ The lower segment of the GN emerges from the lower border of stylopharyngeus muscle.

From the transoral view, the nerve is traced in the plane formed by the styloglossus and stylopharyngeus muscles.

GN has 2 possible relationship with pharyngeal branch of vagus nerve: $75 \%$ cases, pharyngeal branch crosses the GN to innervate pharyngeal wall and $25 \%$ cases, pharyngeal branch of vagus is parallels the course of GN to form the plexus to innervate pharyngeal wall. ${ }^{3}$

The stylopharyngeus muscle is an important landmark as it is identifiable during transoral surgery superiorly with relation to the styloid process, and inferiorly its fibers insert into the pharyngeal constrictors parallel with the palatopharyngeus muscle fibers. ${ }^{3}$

GN gives sensory innervation to the posterior third of the tongue, the vallecula, anterior surface of epiglottis, wall of 
pharynx, tonsil. Etiology of glossopharyngeal neuralgia idiopathic (majority), secondary due to: neoplasm like tongue and tonsillar tumor, compression or injury of the GN by vascular structures, trauma like post tonsillectomy, post styloidectomy, infection like tonsillitis, tuberculosis and eagles syndrome. The left nerve is more often involved than the right. ${ }^{4}$ Glossopharyngeal neuralgia is a rare entity following post tonsillectomy/trans oral styloidectomy.

Several medications and surgical procedures have been proposed for the treatment of GPN. These include carbamazepine, tiapride, rhizotomy of the GN, microvascular decompression (MVD), and gamma knife surgery (GKS). ${ }^{5} \mathrm{MVD}$ is considered to be the first line of surgical treatment in medically refractive GPN. ${ }^{6}$

In our case, patient had recurrent glossopharyngeal neuralgia post-tonsillectomy/trans oral styloidectomy, which got resolved completely after excising a long segment of exposed nerve along with its branches which was visible intraorally. Hence trans-oral approach was chosen for excision of nerve.

\section{CONCLUSION}

Glossopharyngeal neuralgia is a rare entity following post tonsillectomy or trans-oral styloidectomy. Neuralgia may occur if tonsillar bed is exposed following tonsillectomy or injury to muscles around nerve, leaving the nerve exposed. Minimal dissection and intervention to the tonsil bed and suturing tonsillar bed following transoral styloidectomy can prevent post-operative glossopharyngeal neuralgia.
Funding: No funding sources Conflict of interest: None declared Ethical approval: Not required

\section{REFERENCES}

1. Blumenfeld A, Nikolskaya G, Glossopharyngeal Neuralgia. Curr Pain Headache Rep. 2013;17:34350.

2. Wilhour D, Nahas S J, The Neuralgias. Curr Neurol Neurosci Rep. 2018;18:69-76.

3. Wang C, Kundaria S, Fernandez-Miranda J, Duvvuri U. A description of the anatomy of the glossopharyngeal nerve as encountered in transoral surgery. The Laryngoscope. 2016;126(9):2010-5.

4. Swain AR. Patient with chronic glossopharyngeal neuralgia/post-tonsillectomy pain. Case Studies in Pain Management. 2015;45:326-8.

5. Xiang NX, Tan D, Fu P, Zhao HY. Gamma knife radiosurgery for glossopharyngeal neuralgia by targeting the medial cisternal segment of the glossopharyngeal nerve: report of 3 cases. Stereotact Funct Neurosurg. 2015;93:292-6.

6. Palanisamy D, Kyosuke M, Yasuhiro Y, Tsukasa K, Kato Y. Management of recurrent glossopharyngeal neuralgia following microvascular decompression surgery. World Neurosurgery. 2018;117:339-43.

Cite this article as: Mahalingappa AK, Gupta R, Ramakrishnan S. Glossopharyngeal neuralgia due to exposed glossopharyngeal nerve post tonsillectomy and transoral styloidectomy. Int J Otorhinolaryngol Head Neck Surg. 2020;6:1725-8. 